\title{
The Differentiation Analysis between Smart Substation and Comprehensive Automation Substation
}

\author{
Defeng Chen ${ }^{1, a}$, Zhibin Yang ${ }^{1, a}$ Tiecheng Guan ${ }^{2, a}$ Baoshuai Ding 2,a \\ 1 No.39, Siping Street, Heping District, Shenyang, Liaoning, China \\ 2 No.40,Bohai Street East before the District station,Yingkou,Liaoning,China \\ achendefeng27@163.com
}

\begin{abstract}
Keywords: Smart substation,Comprehensive automation substation,Differentiation
Abstract. With the rapid development of smart substation technology, people become more and more anxious about the security of smart substation technology as they can't get the concrete difference between smart substation and comprehensive automation substation in runnning status. In this paper, according to the running smart substation, the core technologies and characters are introduced, and the differences between smart substation and comprehensive automation substation are analyzed in physical structure, information acquisition mode, transmission mode respectively, and the advantages of smart substation are given. Besides, the development trend of smart substation is prospected combined with advanced technology in relevant industry.
\end{abstract}

\section{Introduction}

With the rapid development of smart substation construction, the smart substation has drawn more and more attention as the core and basis. The smart substation is a digitized and networked platform combed with data acquisition, transmission, analysis, processing. It relys on digital substation and builds with advanced sense technology, information technology, communication technology, control technology, artificial intelligence technology and so on. the informatization, automation and interact are implemented in electricity substation.

For the smart substation, the message transmission digitized, information networked, and IED modeling standardized are the basic requirements, data acquisition, transmission, analysis, calculation and processing automatically are the basic functions, and the interact with adjacent substation, grid dispatch systems, power users must realize as required[1]. The smart substation is the requirement for development. But what are the differences intrinsically between smart substation and comprehensive automation substation?

\section{Characters of Smart Substation}

Essentially speaking, comprehensive automation substation is the base of digitized substation, and smart substation is the promotion and upgrade of digitized substation in the development of sense technology, information technology, communication technology, control technology, artificial intelligence technology and so on. The features of smart substation are as follows:

1 Stable and reliable. On the basis of strengthening the reliability of the equipment in the station, smart substation enhances the self diagnosis and self healing ability, realizes the early warning of abnormal fault, and complete the corresponding operation automatically.

2 Primary equipments intelligent. The application of a large number of electronic transformers, intelligent circuit breakers and sensors, not only implements the digital electrical information, but also improves the primary equipments' perception ability of running state[2].

3 Substation information digitization. It lays a solid foundation for the high speed sharing of network information, and makes the information management more convenient[3].

4 Information sharing standardization. "One world, one standard", the standardized information model of substation equipments using IEC61850 standard, improves the interoperability and consistency. Regardless of different manufacturers and different types, equipments can work together. 
5 Advanced application interaction. The unified information model, information digitization and network information interaction break the barriers of information exchange between different systems inside and outside the station, and increase the interactions between the relevant objects of the advanced application system.

\section{The differences analysis between smart substation and comprehensive automation substation}

Compared with comprehensive automation substation, smart substation has been greatly improved in terms of technology advancement, operational reliability and system openness. At present, although there are still some shortcomings in many advanced applications, but the basic frame of construction work from the comprehensive automation substation to smart substation is completed, such as concept, secondary system physical structure, information transmission mode, IED standardized modeling and so on, these are also the differences in essence at current stage.

The differences between smart substation and comprehensive automation substation are as follows:

Physical constructions

Smart Substation has changed in the aspects of function configuration, equipment layout, system construction and so on. The schematic diagram of the physical construction is shown in figure 1.

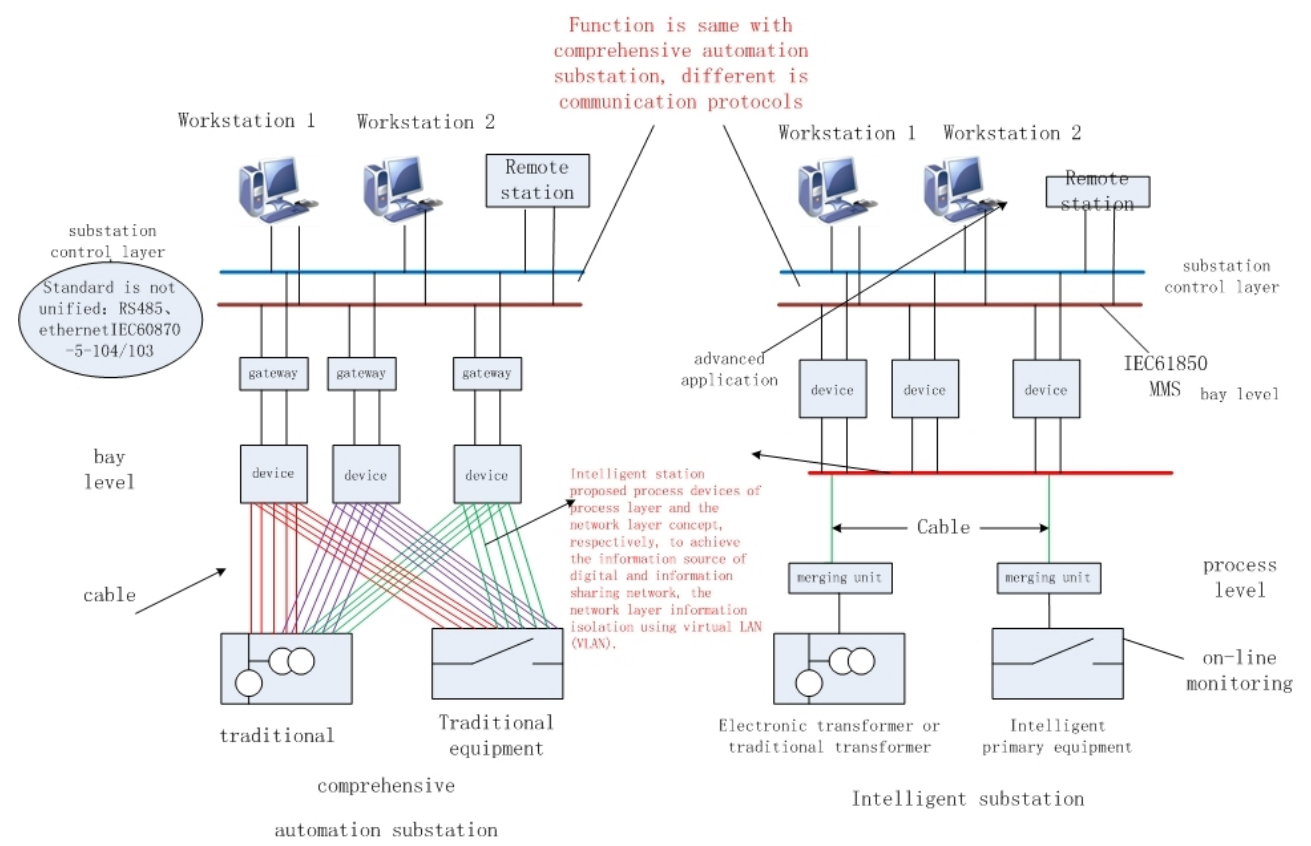

Figure 1 The diagram of the physical construction change between the smart substation and comprehensive automation substation

The brief differences in physical construction are shown in Table 1.

Table 1 The brief differences in physical construction

\begin{tabular}{|c|c|c|}
\hline Comparison Iterm & $\begin{array}{c}\text { Comprehensive automation } \\
\text { substation }\end{array}$ & Smart substation put into operation at present \\
\hline $\begin{array}{c}\text { secondary equipment } \\
\text { layout }\end{array}$ & $\begin{array}{c}\text { group panel layouts in all } \\
\text { buildings }\end{array}$ & $\begin{array}{c}\text { group panel layouts in most buildings or group } \\
\text { panel layouts in integrated warehouse } \\
\text { outdoor cabinet layout a small part }\end{array}$ \\
\hline system architecture & two layers and one network & three layers and two nets[4] \\
\hline connection mode & cable & optical fiber \\
\hline $\begin{array}{c}\text { relay protection } \\
\text { interlocking }\end{array}$ & $\begin{array}{c}\text { logical connective by } \\
\text { secondary relay }\end{array}$ & process network \\
\hline
\end{tabular}

\section{Information acquisition modes}

The biggest differences in the sampling mode are Centralized collection and distributed independent collection, centralized information transmission and distributed transmission, network sharing and 
point to point collection[5]. The sampling model differences between comprehensive automation substation and smart substation are shown as figure 2 and figure 3.
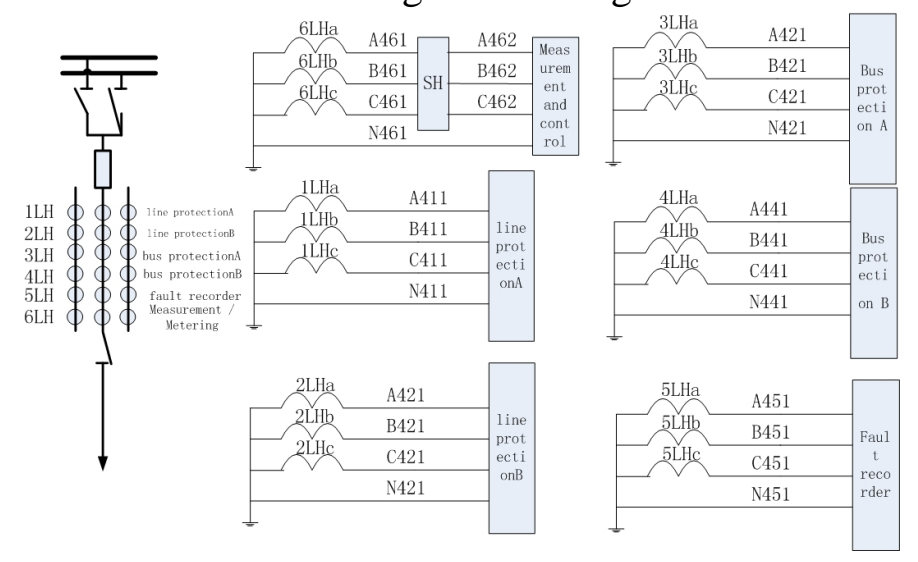

Figure 2 The diagram of typical bay sampling circuit in comprehensive automation substation

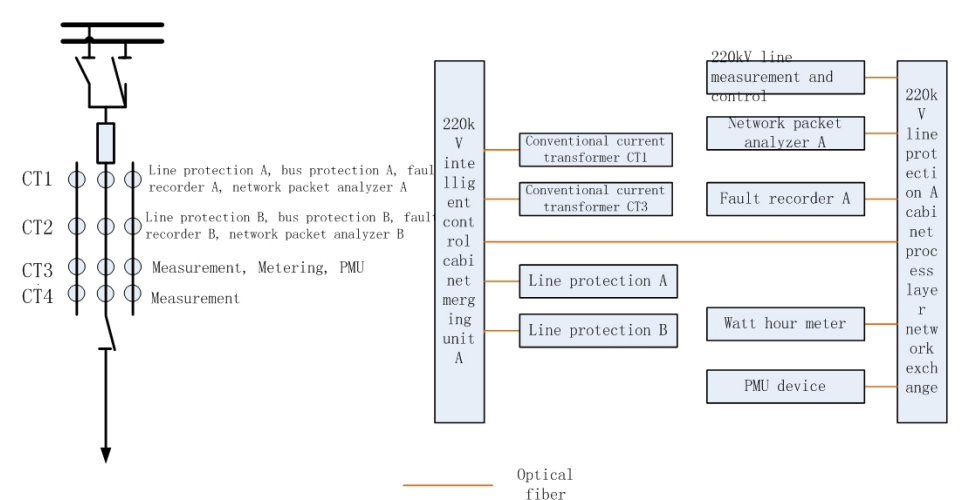

Figure 3 The diagram of typical bay sampling circuit in smart substation

The most difference in sampling mode lies in collecting and dispersing independent collection, centralized information transmission and distributed transmission, network sharing and point to point collection.

3 Information transmission modes

The information transmission modes of comprehensive automation substation and smart substation are shown as figure 4. The two main changes in the way of information transmission is digital information instead of analog information, optical fiber instead of cable.

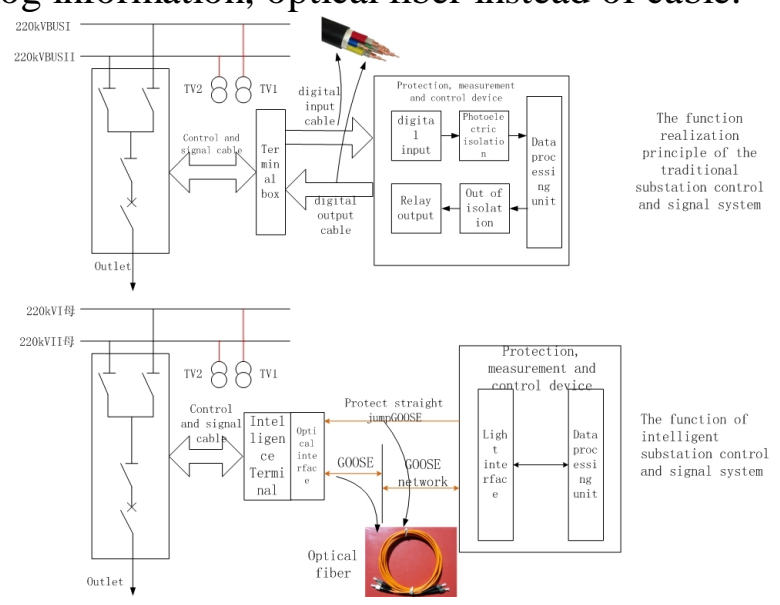

Figure 4 The diagram of information transmission mode changes between the smart substation and comprehensive automation substation 


\section{Future Development Trends of Smart Substation}

At present, the development of Smart Substation is still in the exploratory stage. It has not reached the desired state not only in logic architecture, physical structure, but also in system plan, installation layout, construction mode, operation and maintenance mode and other aspects. With the development of communication technology, cloud computing technology, big data analysis technology and hardware manufacturing technology, the desired state of Smart Substation is gradually reached. The Smart Substation in future should be like this:

1 Smart substation is mainly composed of intelligent primary equipments connected by the power supply and the optical fiber.

2 The cloud platform of power system control and protection is composed of intelligent module integrated with primary equipments and centralized computing center.

3 With control and protection functions deployed automatically and flexibly, when some euqipment is out of work, other equipment can take over the functions carried by damaged equipment immediately.

4 Electric companies can buy the control and protection functions most suitable and most desired ,but do not need to buy hardware equipment.

5 Maintenance personnel can replace the equipments out of work without configuration which can plug and play;

6 The operator can visualize all information about the production, transportation, test, failure and operation of any equipment.

\section{References}

[1] Feng Jun, Principle and testing technology of Smart Substation, China Electric Power Press, 2013.

[2] ZHANG You-ming, GAO Zhong-ji, HUANG Xu, Intelligent Substation Technology Research and Analysis, Northeast Electric Power Technology, 2012, (5): 1-3.

[3] ZHANG Pei-chao, GAO Xiang, System Architecture of Digitized Substation, Power System Technology, 2006, 30(24): 73-77.

[4] LI Zhao-qi, YANG Gui,. Research on Intelligent Substation Communication Network Architecture, Northeast Electric Power Technology, 2014, 35(4):27-30.

[5] ZHANG Qi, ZHANG Shou-dong, HU Wei, Channel Combined Commissioning Test between Smart Substation and Conventional Substation, Northeast Electric Power Technology, 2012, 33(2): 35-37. 